\title{
CuO@NiO nanocomposite catalysed synthesis of biologically active Indenoisoquinoline derivatives
}

Manish Rawat and Diwan S. Rawat*a

${ }^{a}$ Department of Chemistry, University of Delhi, Delhi-110007, India.

*corresponding author email: dsrawat@chemistry.du.ac.in

Fax: 91-11-27667501; Tel: 91-11-27662683

Electronic Supplementary Information (ESI) includes TEM of recycled $\mathrm{CuO} @ \mathrm{NiO}$ nanocatalyst; Green chemistry metric calculations, ${ }^{1} \mathrm{HNMR}$ and ${ }^{13} \mathrm{C}$ NMR spectra of all compounds.

Total No of Pages: 22, Total No of Tables: 0, Total number of Figures: 1.

Table of contents

\begin{tabular}{|c|l|c|}
\hline $\begin{array}{c}\text { Serial } \\
\text { number }\end{array}$ & \multicolumn{1}{c|}{ Contents } & $\begin{array}{c}\text { Page } \\
\text { number }\end{array}$ \\
\hline 1. & General Remarks & $\mathrm{S} 2$ \\
\hline 2. & TEM image of recycled CuO@NiO & $\mathrm{S} 2$ \\
\hline 3. & Calculation of Green chemistry metrices of our method & S3-S4 \\
\hline 4. & Calculation of Green chemistry metrices of reported method & S4-S5 \\
\hline 5. & References & S5 \\
\hline 6. & ${ }^{1} \mathrm{H}$ and ${ }^{13} \mathrm{C}$ spectra of compounds & S6-S22 \\
\hline
\end{tabular}




\section{General Remarks}

Chemicals and solvents were purchased from Sigma Adrich, Alfa-Aesar and Merck India Pvt. ${ }^{1} \mathrm{H}$ and ${ }^{13} \mathrm{C}$ spectra were recorded on a Jeol Spectrospin spectrometer at $400 \mathrm{MHz}$ and 100 MHz respectively by keeping TMS as internal standard. Chemical shift values were recorded in terms of $\delta$ and coupling constants $(\mathrm{J})$ are in hertz $(\mathrm{Hz})$. Mass spectral data was recorded on Agilent G6530AA (LC-HRMS-Q-TOF) model of High-resolution liquid chromatography mass spectrometer with Quadrupole Time-of-flight at USIC (University Science Instrument Centre), University of Delhi, Delhi, India. FT-IR spectra were recorded on Perkin Elmer. Field emission scanning Electron microscopy (FESEM) measurement was performed on a Zeiss Gemini SEM 500 thermal field emission type with acceleration voltage $0.02-30 \mathrm{kV}$ at USIC (University Science Instrument Centre), University of Delhi, Delhi, India. Transmission electron microscopy (TEM) was obtained on a TECNAI G20 HR-TEM 200kV at SAIF (sophisticated analytical instrumentation facility), AIIMS, New Delhi, India. X-ray diffraction (XRD) patterns were recorded on Rigaku Rotaflex spectrometer at $2 \theta$ range of 10 $90^{\circ}$ with $\mathrm{Cu} \mathrm{K} \alpha$ radiation. The elemental composition and electronic structure analysis were obtained from X-ray photoelectron spectra (XPS) of PHI Versa Probe II instrument equipped with a monochromatic $\mathrm{Al} \mathrm{K} \alpha$ source at Department of Chemistry, Indiana University, Bloomington, Indiana 47405, United States. ICP-MS was measured on Agilent ICP-MS 7900 with UHMI at the ICP-MS Lab, (CRF Adopted Facility), IIT Delhi, INDIA. BET experiment was performed on BET surface area analyzer, Quantachrome Instruments, ASI-CI-11 at USIC (University Science Instrument Centre), University of Delhi, Delhi, India.

\section{TEM image of recycled $\mathrm{CuO} @ \mathrm{NiO}$ nanocomposites}

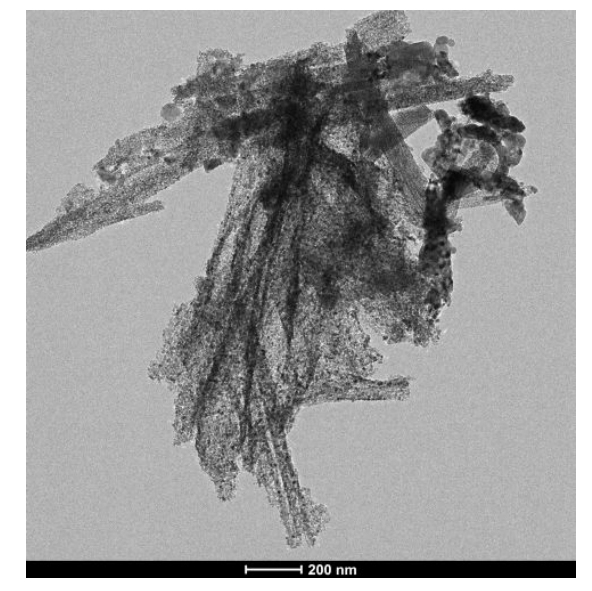

Figure S1: TEM image of recycled $\mathrm{CuO} @ \mathrm{NiO}$ nanocomposites 


\section{Calculation of Green chemistry metrices for $3 a$ of our method}<smiles>O=C(Nc1ccccc1)c1ccccc1I</smiles>

$1 \mathrm{a}$<smiles>O=C1C(=O)C2CCCC1C2</smiles>

2

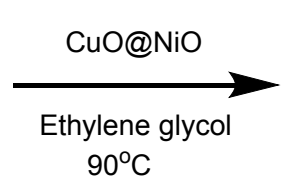
$90^{\circ} \mathrm{C}$<smiles>O=C1c2ccccc2-c2c1c1ccccc1c(=O)n2-c1ccccc1</smiles>

$323.35 \mathrm{~g} / \mathrm{mol}$

0.21

m.mol

0.25

0.25

$68 \mathrm{mg}$

\section{E-factor:}

The ideal value of E-factor is zero.

$\mathrm{E}$-factor $=[$ total mass of raw materials - the total mass of product $] /$ mass of product.

E-factor of $\mathbf{3 a}=[(80.78+36.54)-68] / 68$

$$
=0.72 \text {. }
$$

Process mass intensity (PMI):

$\mathrm{PMI}=\sum$ (mass of stoichiometric reactants) $/[$ mass of product $]$

$$
\begin{aligned}
& =(80.78+36.54) / 68 \\
& =1.72 .
\end{aligned}
$$

\section{Reaction mass efficiency (RME):}

$\mathrm{RME}=\left[\right.$ mass of product $/ \sum$ (mass of stoichiometric reactants $\left.)\right] \times 100$

$$
\begin{aligned}
& =[68 /(80.78+36.54)] \times 100 \\
& =57.96 \%
\end{aligned}
$$

\section{Carbon efficiency (CE):}

$\mathrm{CE}$ denotes the percentage of carbon in the reactants that remains in the product.

$\mathrm{CE}=[$ Amount of carbon in product/ Total carbon present in reactants] x 100

$=[$ no. of moles of product $\mathrm{x}$ no. of carbons in product $/$ (moles of 1a x carbons in 1a + moles of $2 \times$ carbons in 2)] $\mathrm{x} 100$

$=[0.21 \times 22 /(0.25 \times 13+0.25 \times 9)] \times 100$

$=[4.62 /(3.25+2.25)] \times 100$

$=84 \%$ 
Turnover number (TON): The number of moles of substrate that converted by a mole of catalyst before its inactivation. TON is calculated for 5 cycles of the reaction with $5 \mathrm{mg}$ of CuO@NiO.

$\mathrm{TON}=[$ No. of moles of product $] \div[$ No. of moles of catalyst $]$

TON of compound 3a: $[0.21(1)+0.205(2)+0.2(3)+0.197(4)+0.192(5)+0.185(6)] /[$ $0.063]$

TON of compound 3a: 36.69 .

\section{Calculation of Green chemistry metrices for 3a of reported Methods ${ }^{1}$ :}<smiles>O=C(Nc1ccccc1)c1ccccc1I</smiles>

1a<smiles>O=C1CC(=O)c2ccccc21</smiles>

2

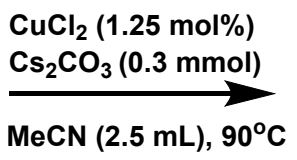

$\operatorname{MeCN}(2.5 \mathrm{~mL}), 90^{\circ} \mathrm{C}$

$146.15 \mathrm{~g} / \mathrm{mol}$<smiles></smiles>

$323.35 \mathrm{~g} / \mathrm{mol}$

FW

$323.13 \mathrm{~g} / \mathrm{mol}$

0.37

0.14

m.mol

0.25

$54.07 \mathrm{mg}$

$45.27 \mathrm{mg}$

\section{E-factor:}

The ideal value of E-factor is zero.

E-factor $=[$ total mass of raw materials - the total mass of product $] /$ mass of product.

E-factor of 3a $=\left[\left(80.78+54.07+2.12\left(\mathrm{CuCl}_{2}\right)+97.50\left(\mathrm{Cs}_{2} \mathrm{CO}_{3}\right)+1972.50(\mathrm{MeCN})\right)-\right.$ $45.27] / 45.27$

$$
=47.75 \text {. }
$$

Process mass intensity (PMI):

$\mathrm{PMI}=\sum$ (mass of stoichiometric reactants + solvent $) /[$ mass of product $]$ $=48.75$.

\section{Reaction mass efficiency (RME):}

$\mathrm{RME}=\left[\right.$ mass of product $/ \sum$ (mass of stoichiometric reactants $\left.)\right] \times 100$

$$
\begin{aligned}
& =[45.27 /(80.78+54.07)] \times 100 \\
& =33.57 \%
\end{aligned}
$$

\section{Carbon efficiency (CE):}

$\mathrm{CE}$ denotes the percentage of carbon in the reactants that remains in the product. 
$\mathrm{CE}=[$ Amount of carbon in product/ Total carbon present in reactants $] \times 100$

$=[$ no. of moles of product $\mathrm{x}$ no. of carbons in product / (moles of 1a x carbons in 1a + moles of $2 \mathrm{a} x$ carbons in $2 \mathrm{a}+$ moles of $3 \mathrm{a} \times$ carbons in $3 \mathrm{a})] \times 100$

$=[0.14 \times 22 /(0.25 \times 13+0.37 \times 9)] \times 100$

$=[3.08 /(3.25+3.33)] \times 100$

$=46.81 \%$

\section{Turnover number (TON):}

$\mathrm{TON}=[$ No. of moles of product $] \div[$ No. of moles of catalyst $]$

TON of compound 3a: [ $0.14(1)] /[0.0125]$

TON of compound 3a: 11.2 .

\section{Reference:}

1. Huang, C. Y.; Kavala, V.; Kuo, C. W.; Konala, A.; Yang, T. H.; Yao, C. F. Synthesis of biologically active indenoisoquinoline derivatives via a one-pot copper (II)-catalyzed tandem reaction. J. Org. Chem. 2017, 82, 1961-1968, DOI: 10.1021/acs.joc.6b02814. 


\section{6. ${ }^{1} \mathrm{H}$ and ${ }^{13} \mathrm{C}$ Spectra of compounds}

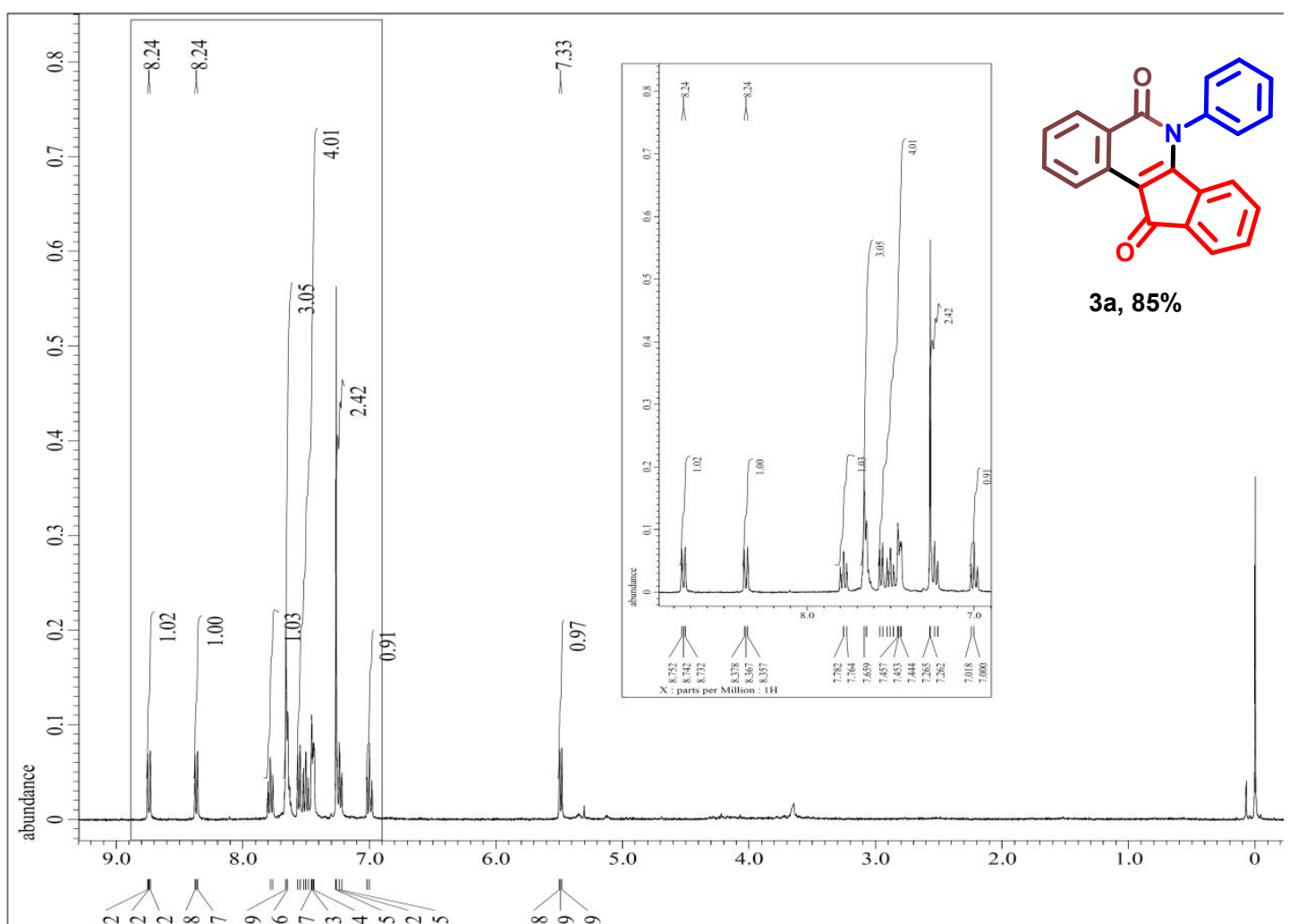

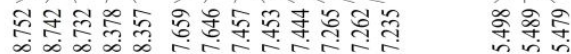

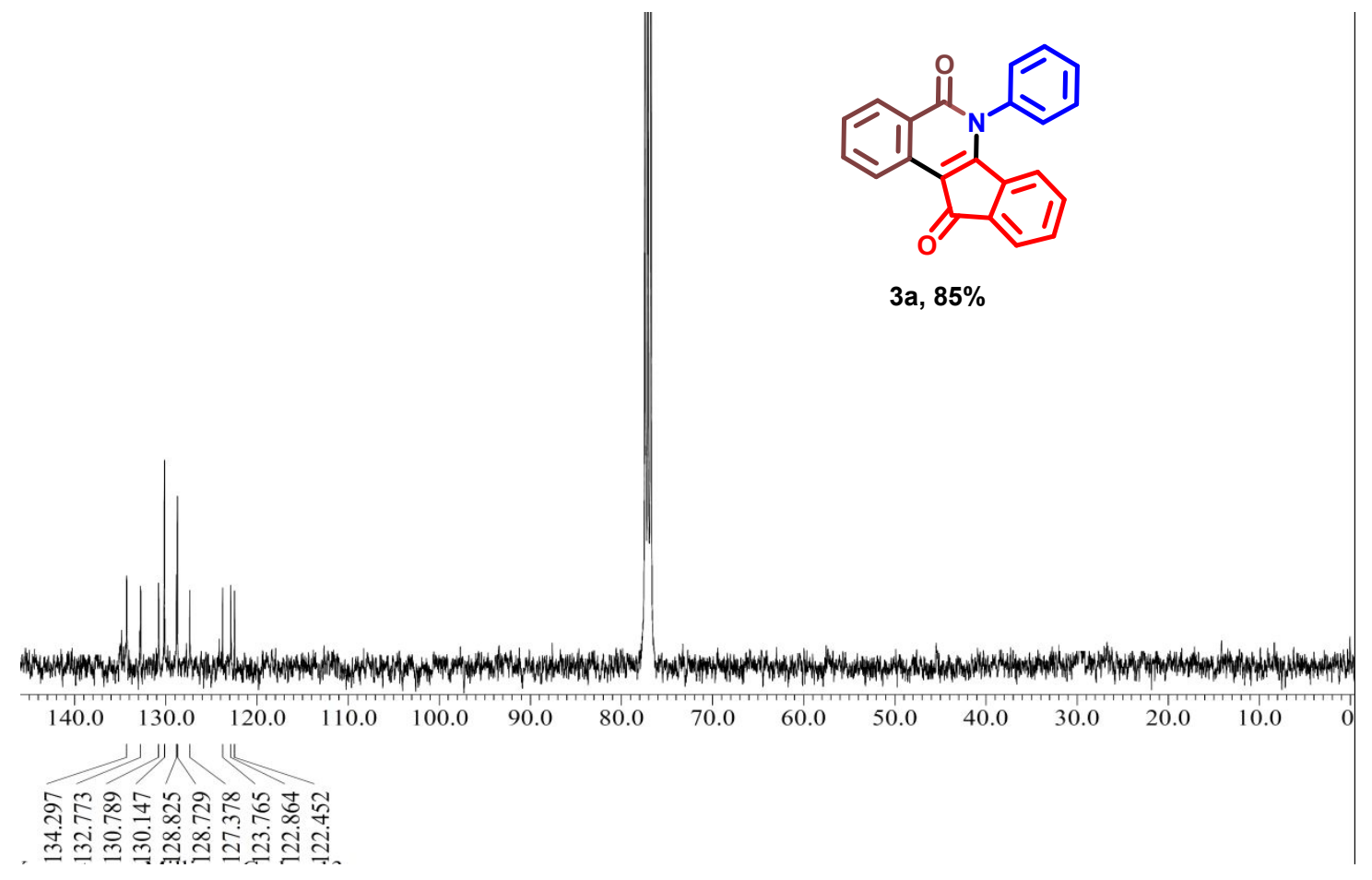



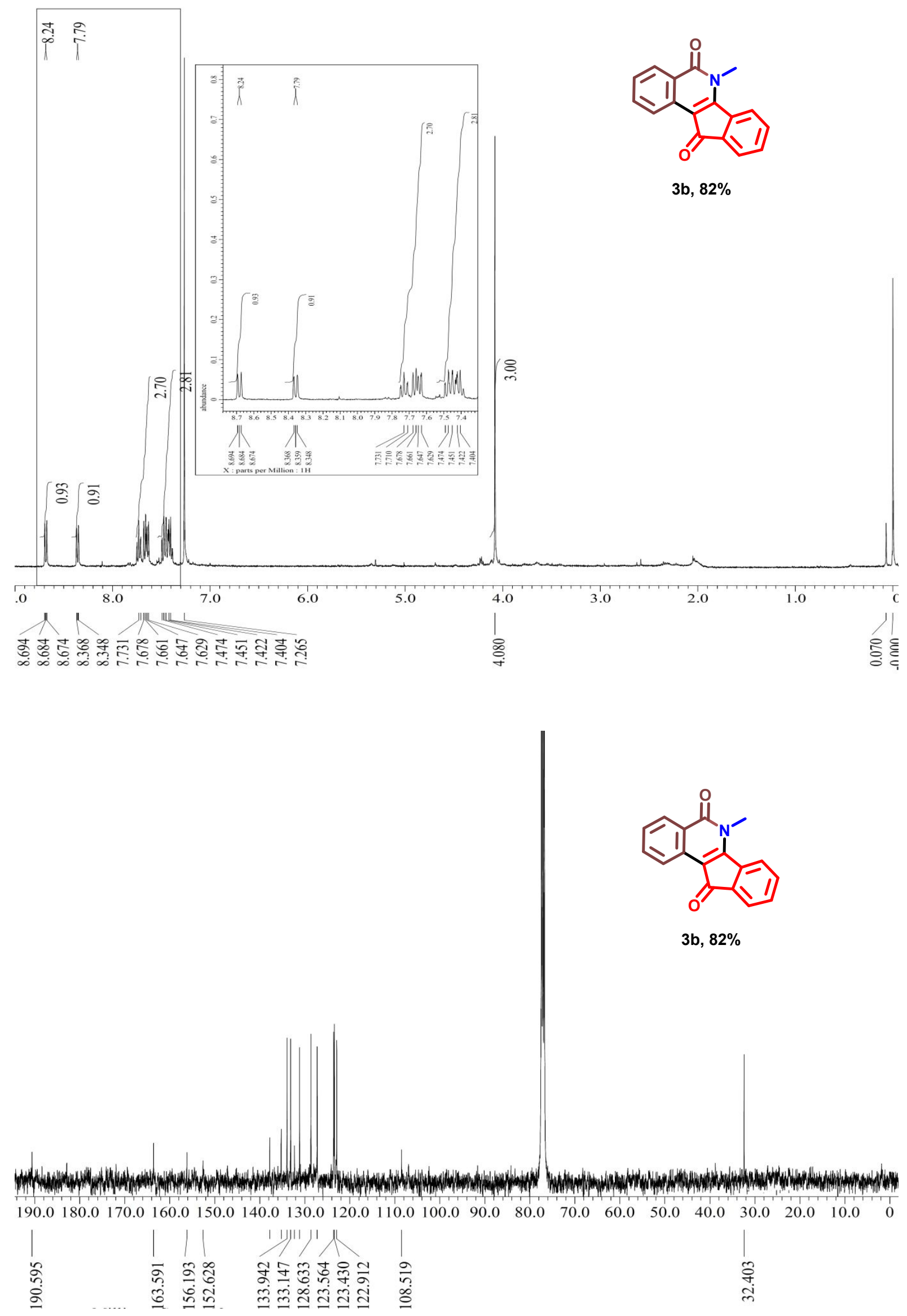

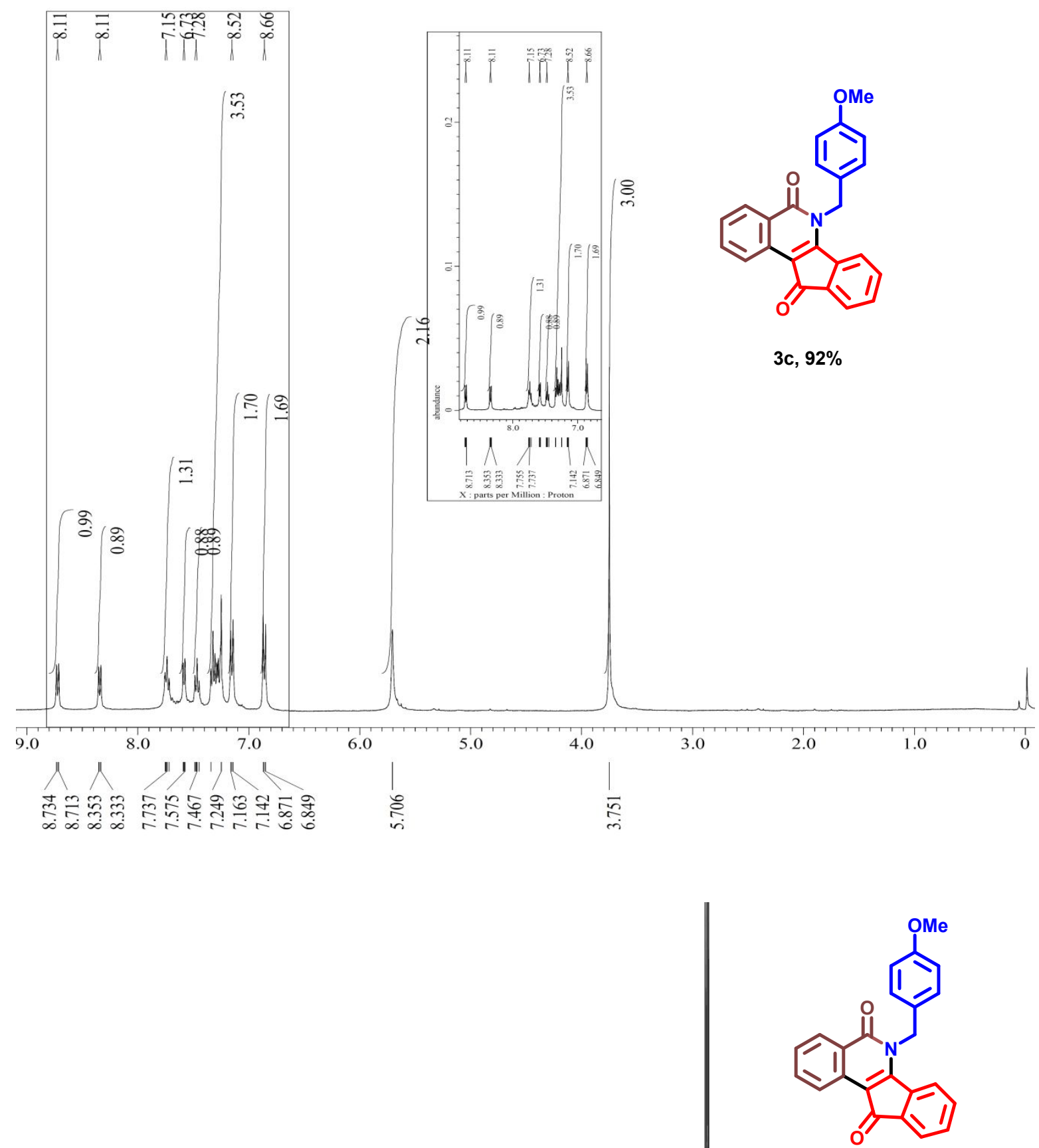

$3 c, 92 \%$

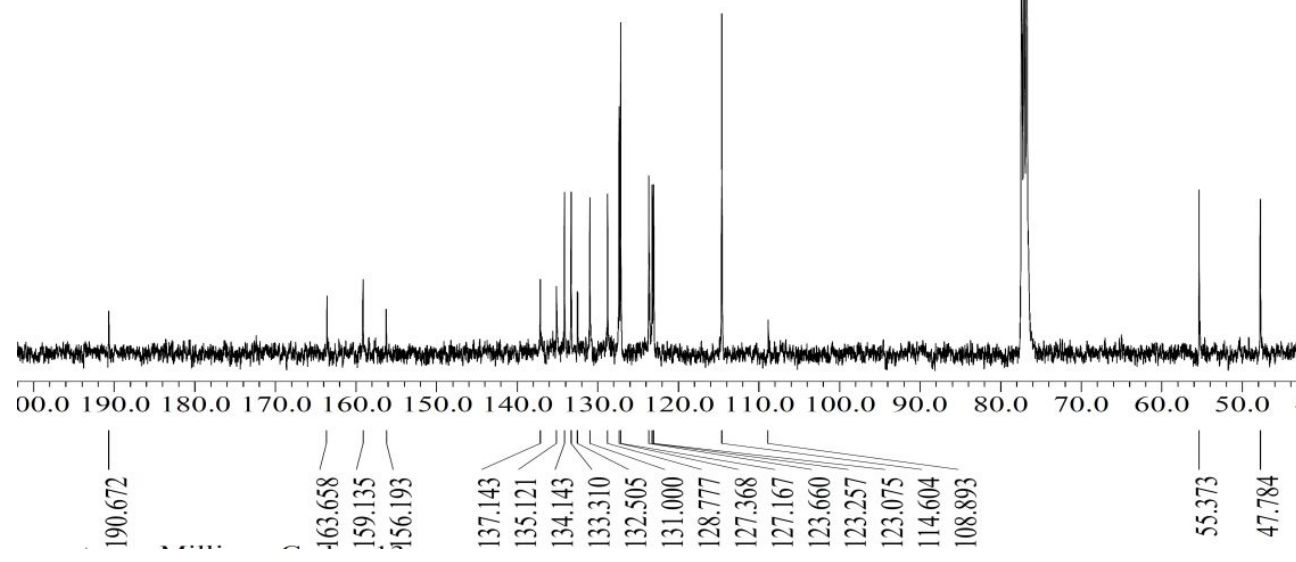



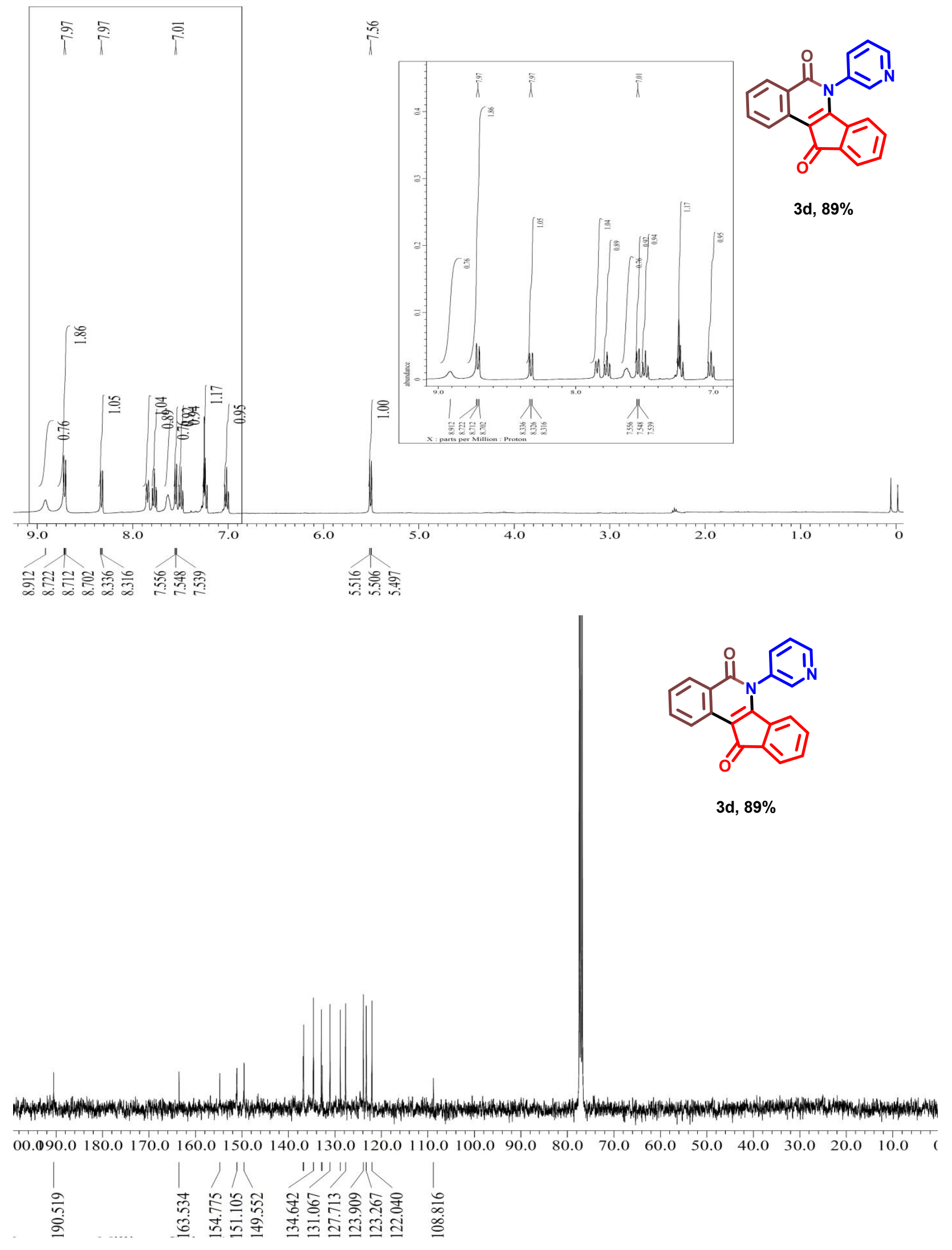

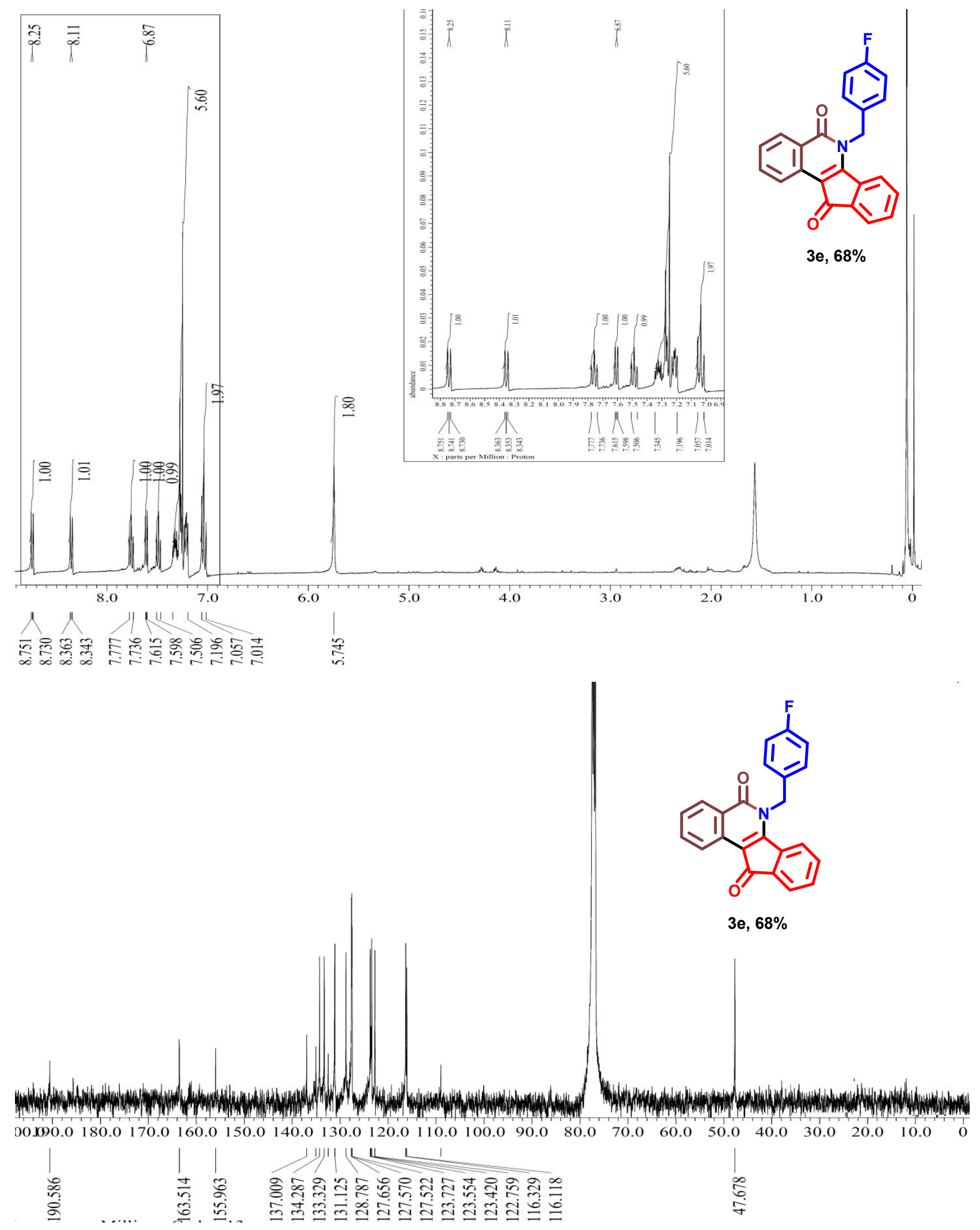

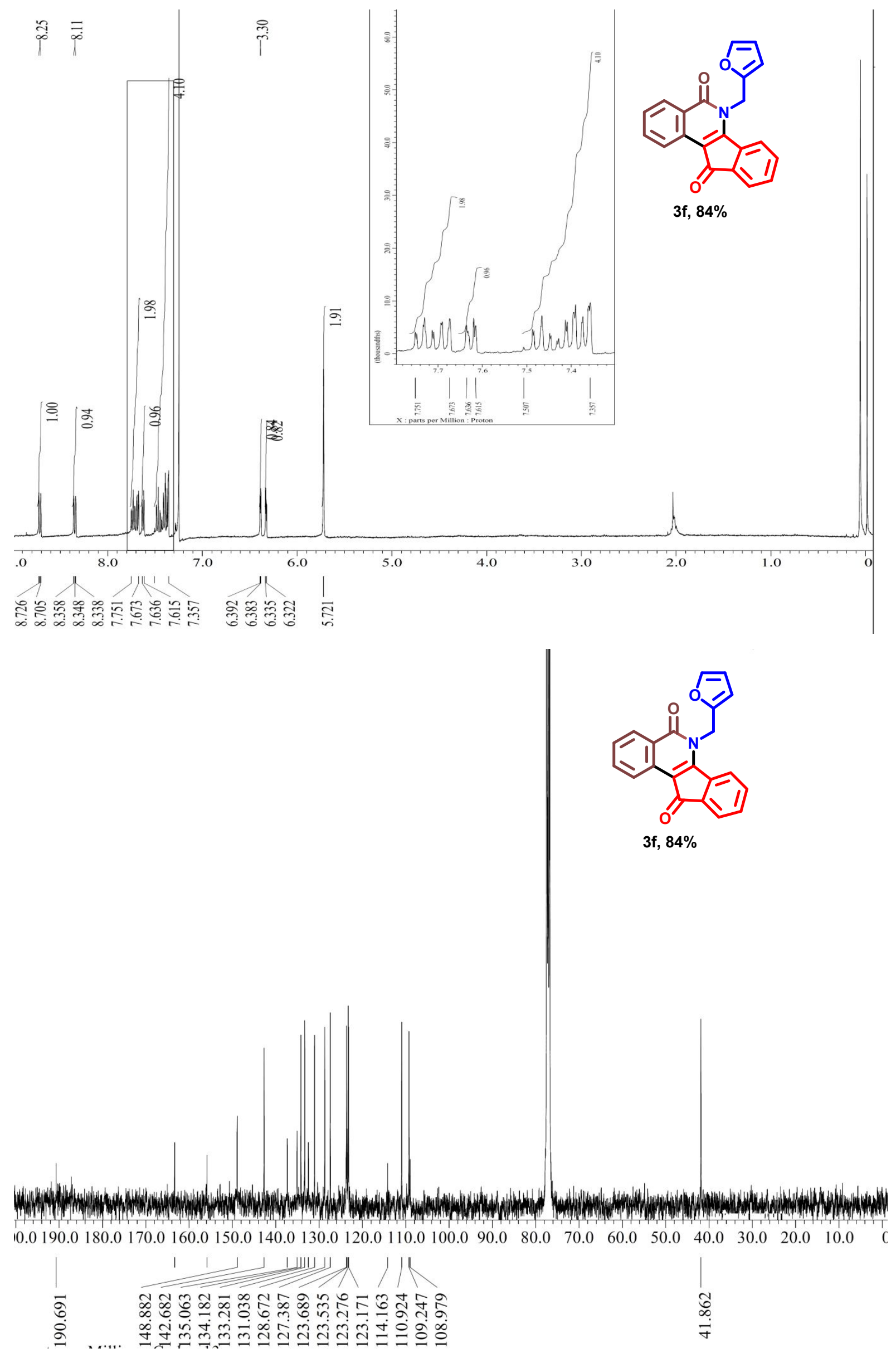

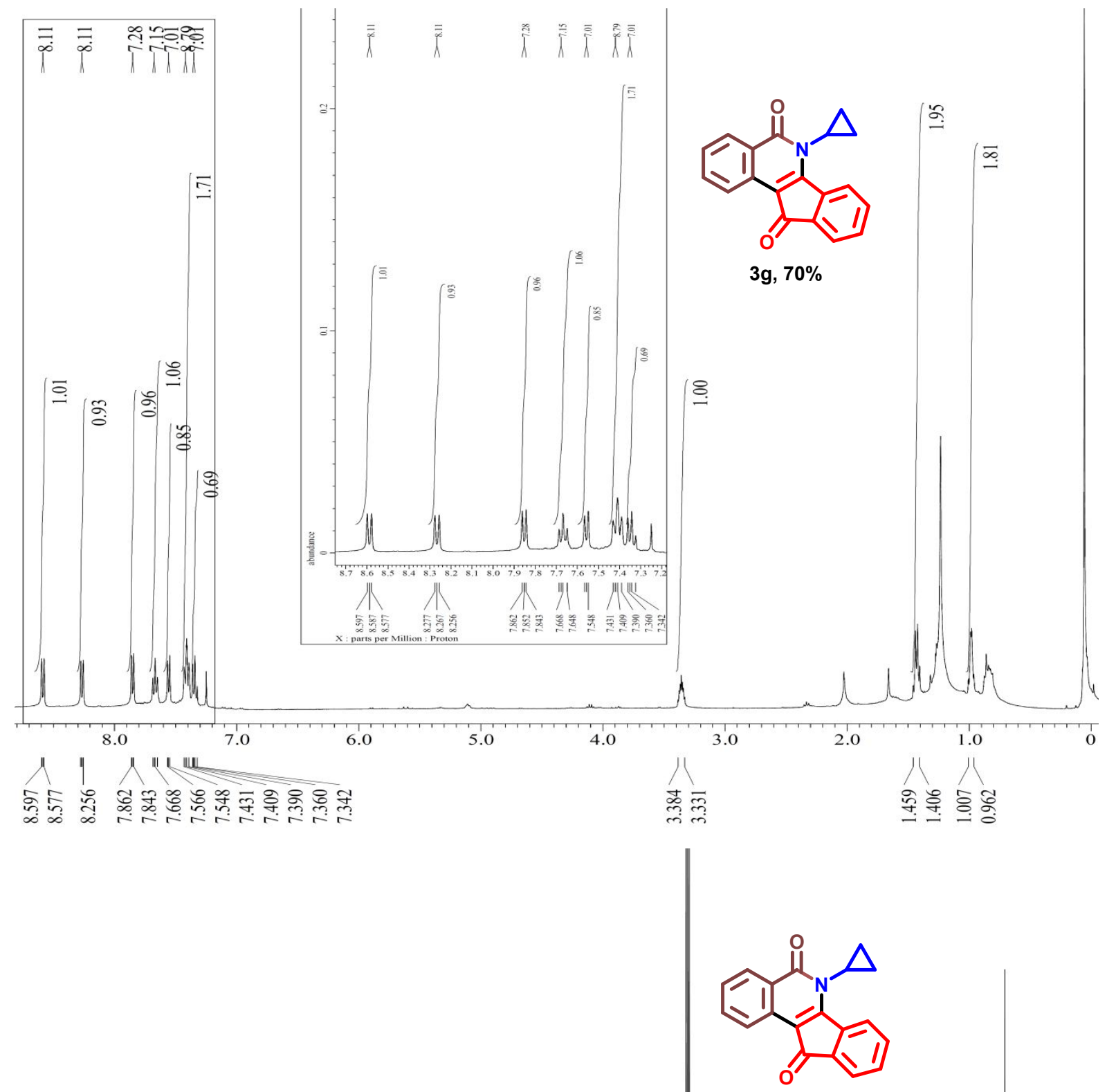

$3 g, 70 \%$

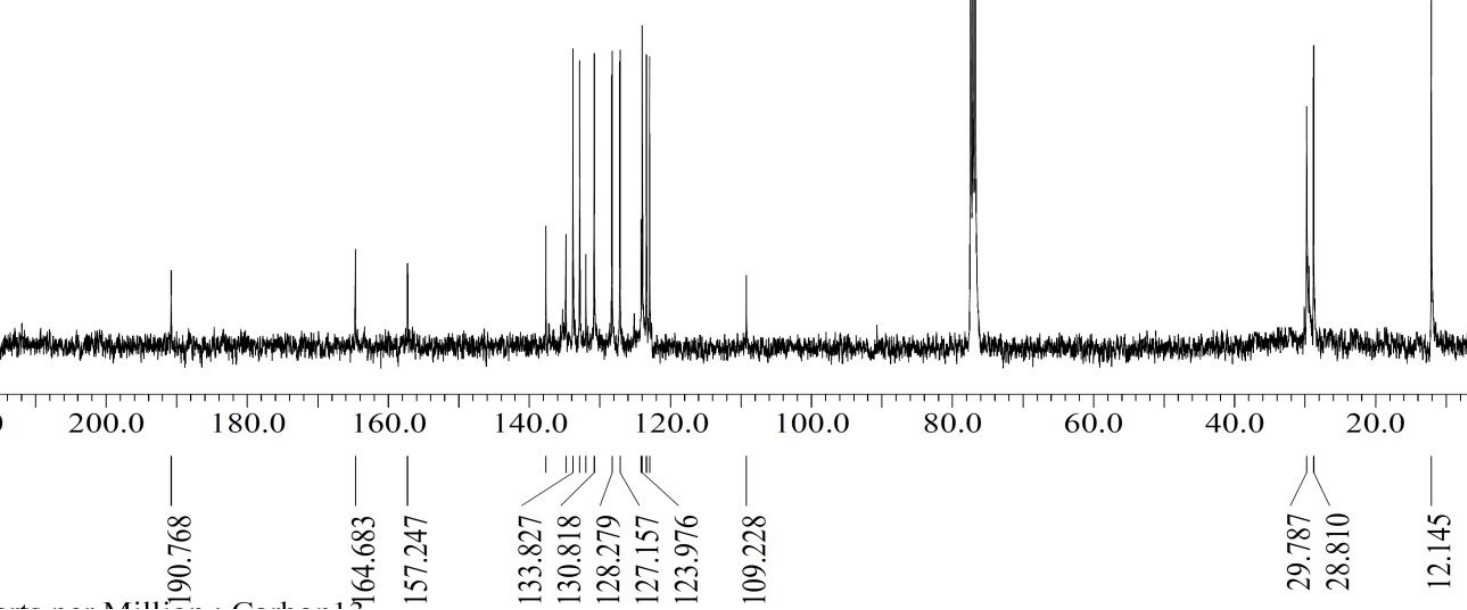



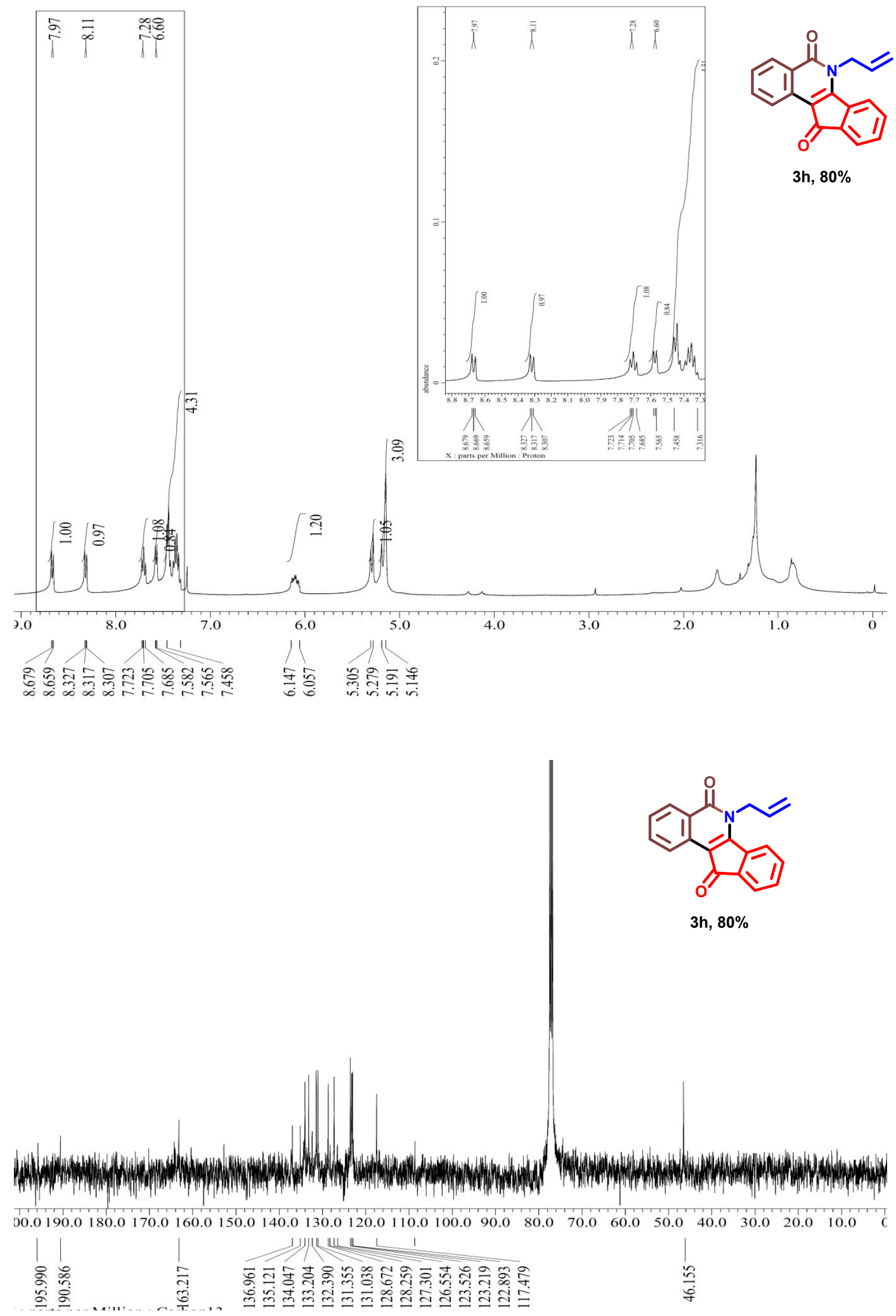

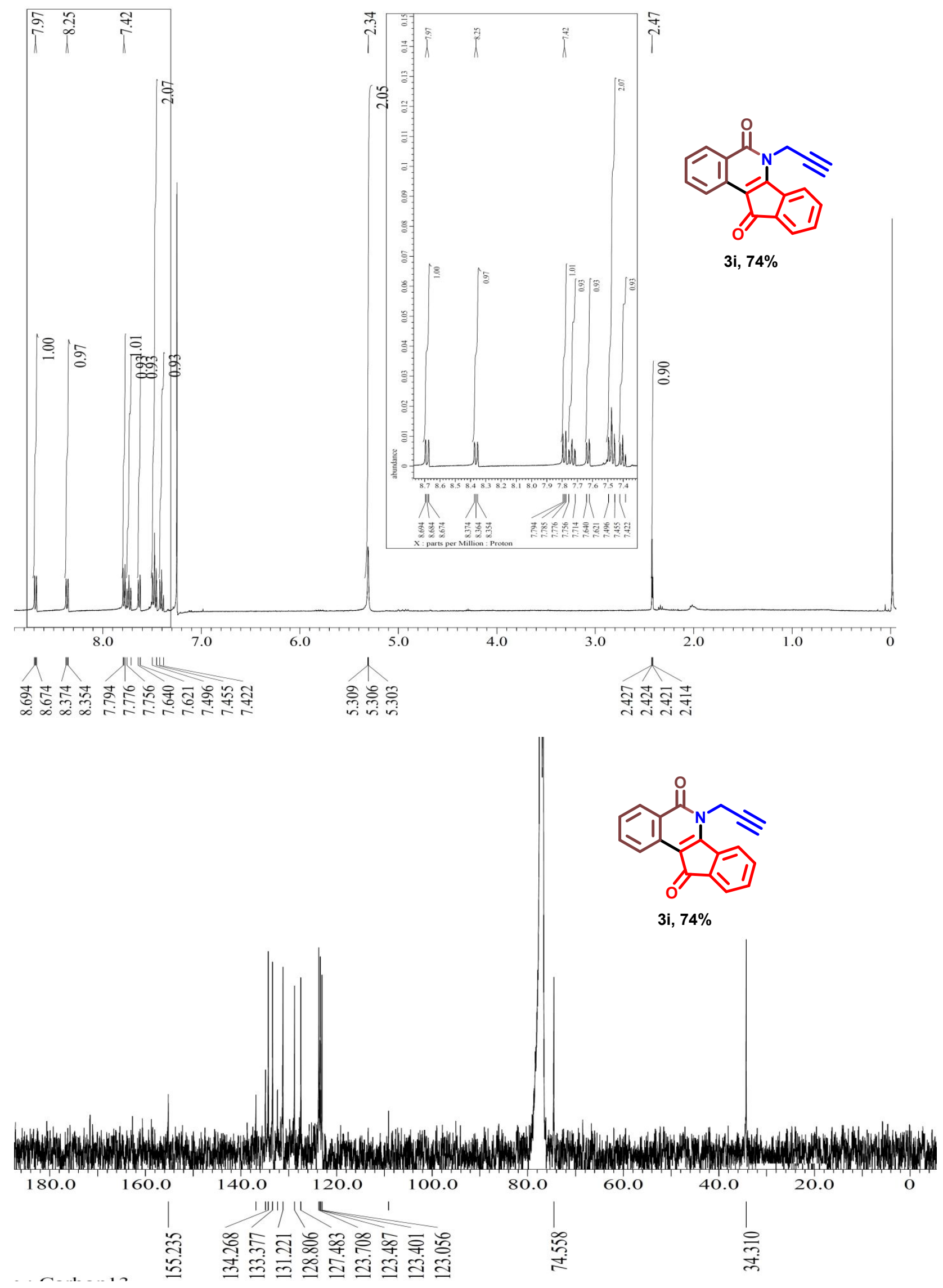

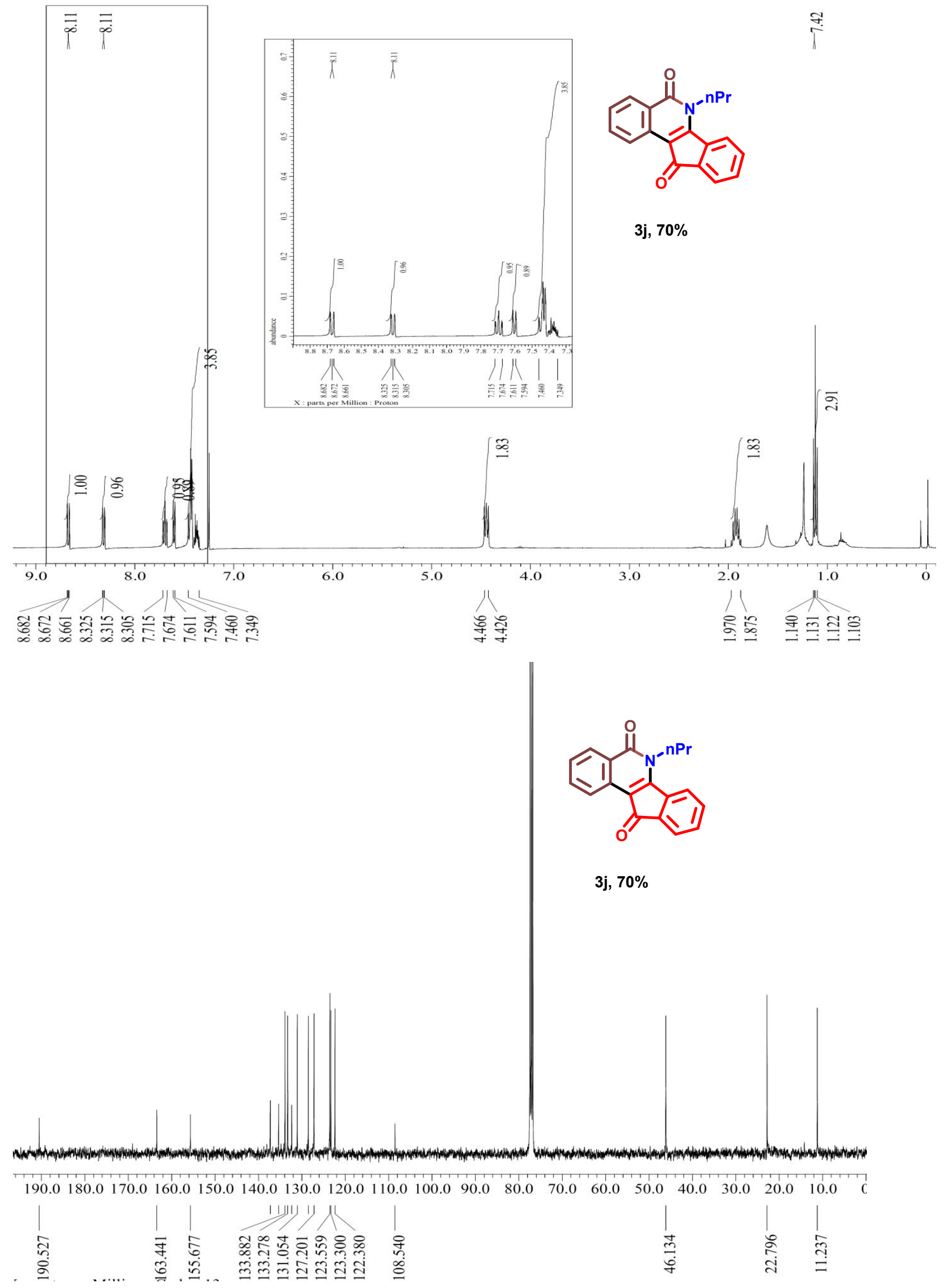

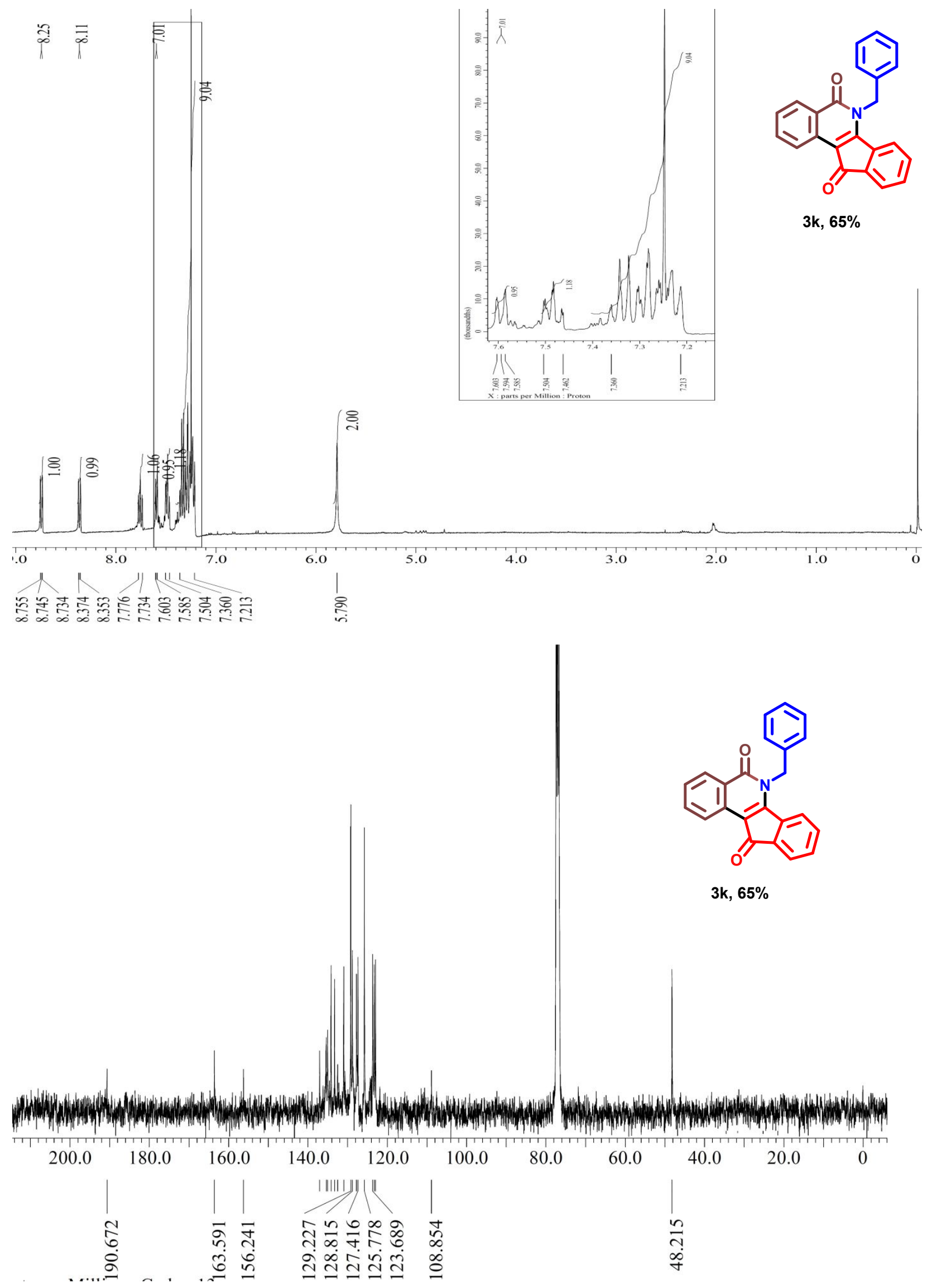

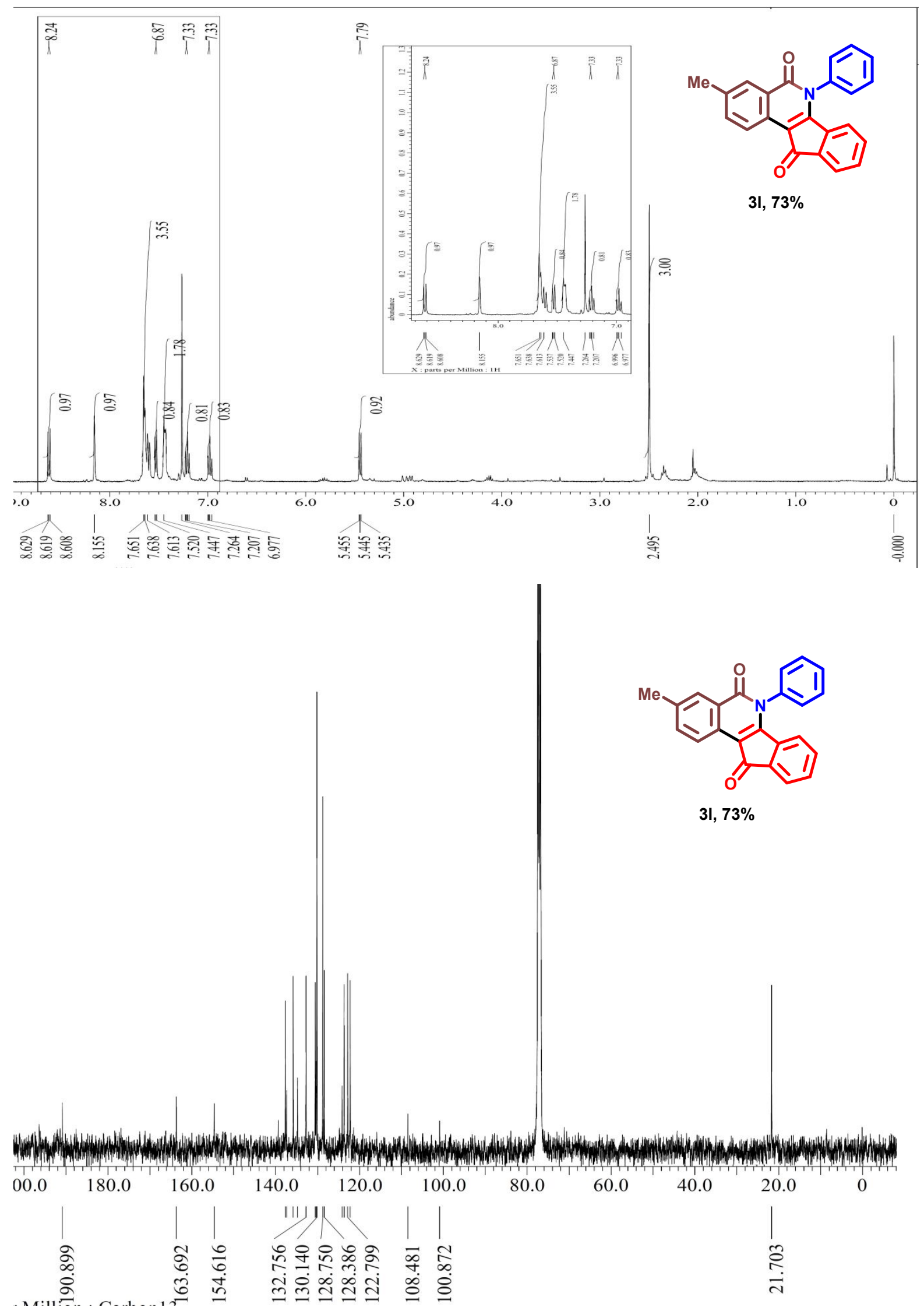

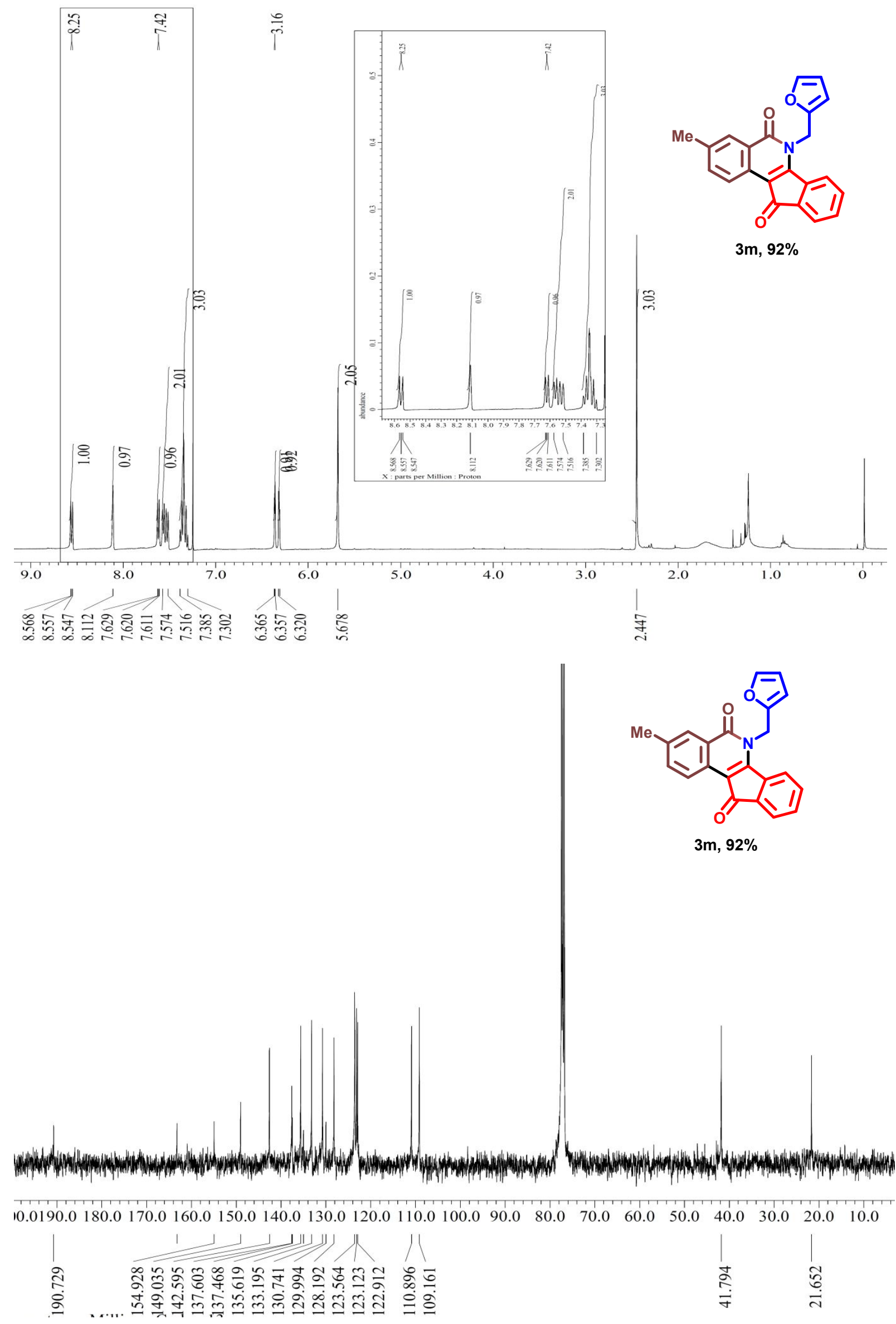

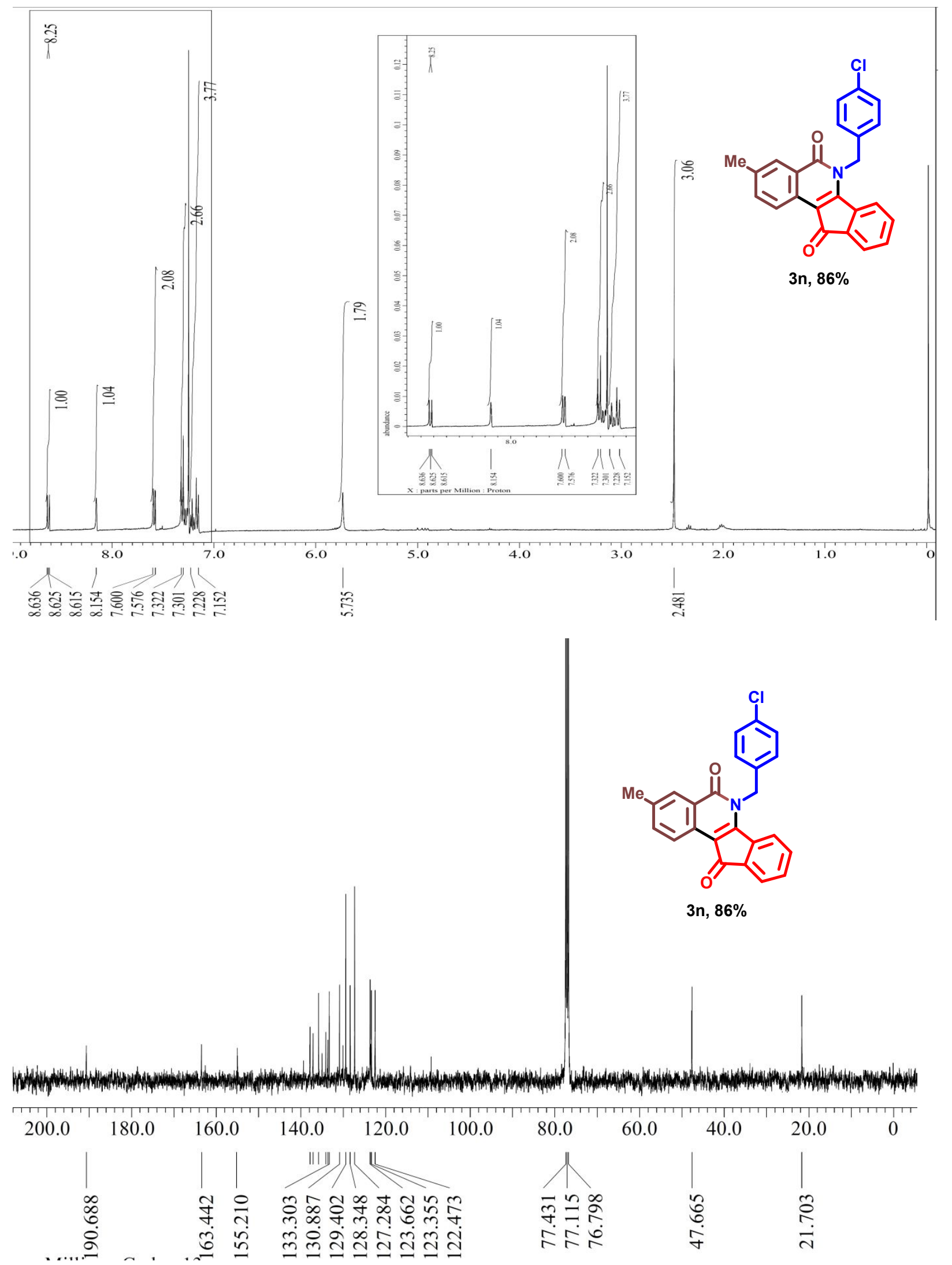

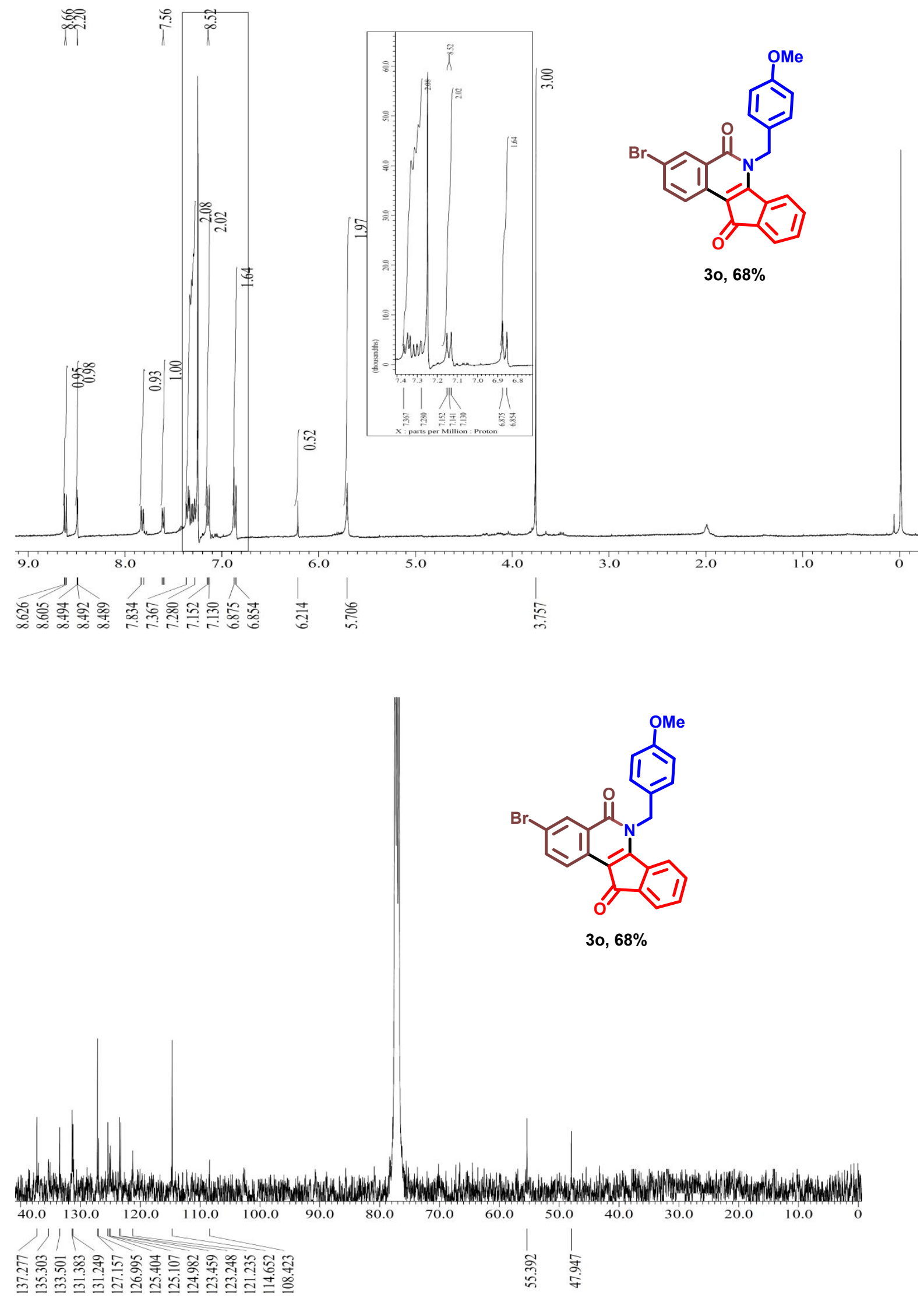

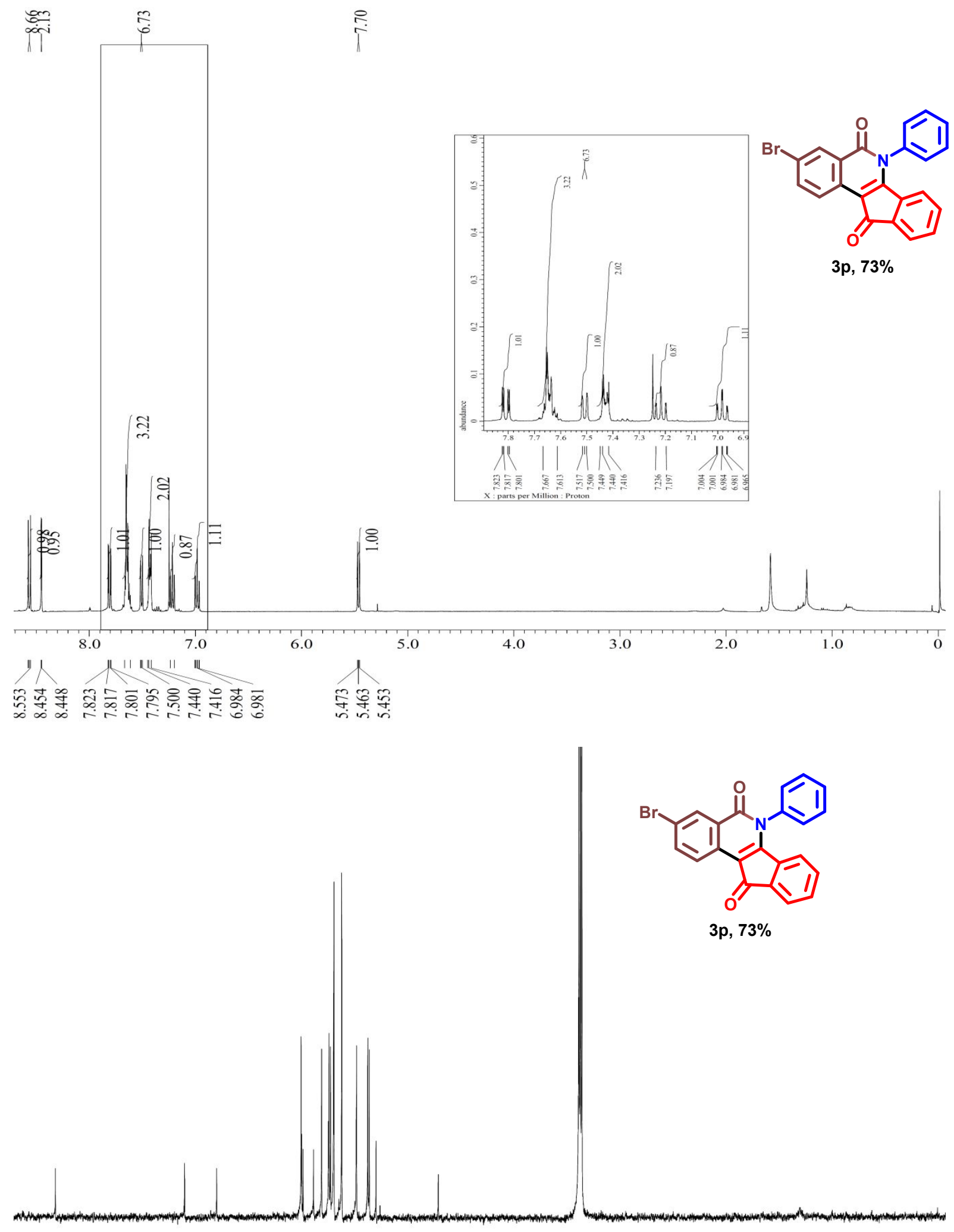

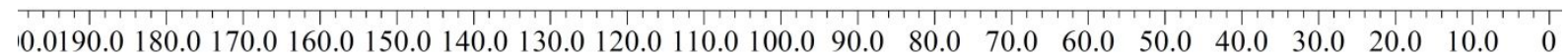

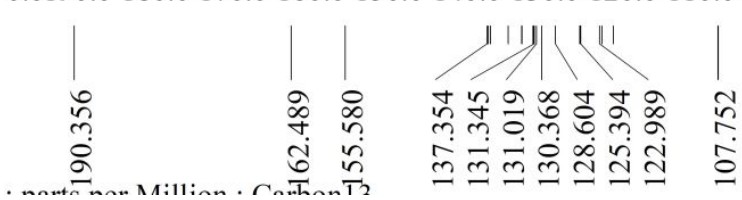



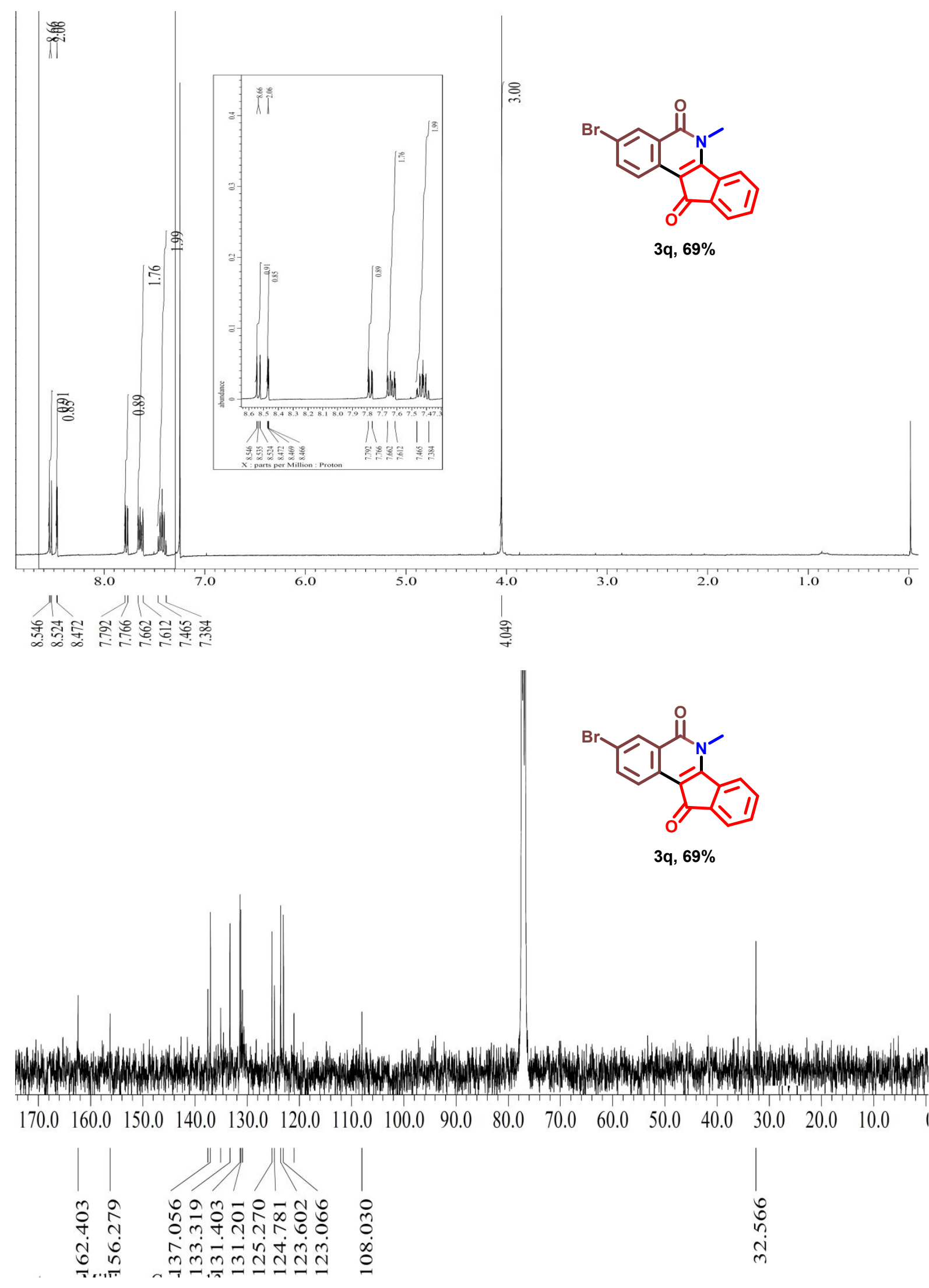